\title{
Erratum to: Stabilization of mineral oil hydrocarbons in recycled paper pulp by organo-functionalized mesoporous silicas and evaluation of migration to food
}

\author{
Enrico Buscaroli ${ }^{1}$ - Daniele Bussini ${ }^{2}$ - Chiara Bisio ${ }^{3,4}$ - Daniela Montecchio ${ }^{1}$. \\ Graziano Elegir $^{2}$ • Davide Garbini ${ }^{5} \cdot$ Leonardo Marchese $^{3,4} \cdot$ Ilaria Braschi $^{1,4}$
}

Published online: 18 April 2017

(C) Springer-Verlag Berlin Heidelberg 2017

\section{Erratum to: Eur Food Res Technol \\ DOI 10.1007/s00217-017-2867-5}

Unfortunately, the given name and family name of all authors were incorrectly published in the original publication. The correct given name and family name should read as follows:

\section{Enrico Buscaroli \\ Daniele Bussini \\ Chiara Bisio \\ Daniela Montecchio \\ Graziano Elegir \\ Davide Garbini \\ Leonardo Marchese \\ Ilaria Braschi}

The original article has been updated.

The online version of the original article can be found under doi:10.1007/s00217-017-2867-5.

Ilaria Braschi

ilaria.braschi@unibo.it

1 Department of Agricultural Sciences, University of Bologna, Bologna, Italy

2 INNOVHUB-SSI, Pulp and Paper Business Area, Milan, Italy

3 Department of Science and Technological Innovation, University of Eastern Piedmont A. Avogadro, Alessandria, Italy

4 Interdisciplinary Nano-SiSTeMI Centre, University of Eastern Piedmont A. Avogadro, Alessandria, Italy

5 Coop Italia s.c.a.r.l., Casalecchio di Reno, Bologna, Italy 